\title{
A Short review on the use of renewable energies and model predictive control in buildings
}

\author{
Jose Maria Santos-Herrero \\ University of the Basque Country (UPV/EHU) / ENEDI Research Group, Thermal Engineering Department, \\ Faculty of Engineering of Bilbao, Alda. Urkijo s/n, 48013 Bilbao, Spain, jmsantos005@ikasle.ehu.es, \\ orcid.org/0000-0002-2991-0126 \\ Jose Manuel Lopez-Guede \\ University of the Basque Country (UPV/EHU), Systems and Automatic Control Department, University \\ Faculty of Engineering of Vitoria, C/ Nieves Cano 12, 01006 Vitoria-Gasteiz, Spain, jm.lopez@ehu.es, \\ orcid.org/0000-0002-5310-1601, tel. +0034945014084

\section{Ivan Flores} \\ University of the Basque Country (UPV/EHU) / ENEDI Research Group, Thermal Engineering Department, \\ Faculty of Engineering of Bilbao, Alda. Urkijo s/n, 48013 Bilbao, Spain, ivan.flores@ehu.eus, \\ orcid.org/0000-0003-3379-8218
}

Arrived: 26.10.2017 Accepted: 09.12.2017 Published: 11.12.2017

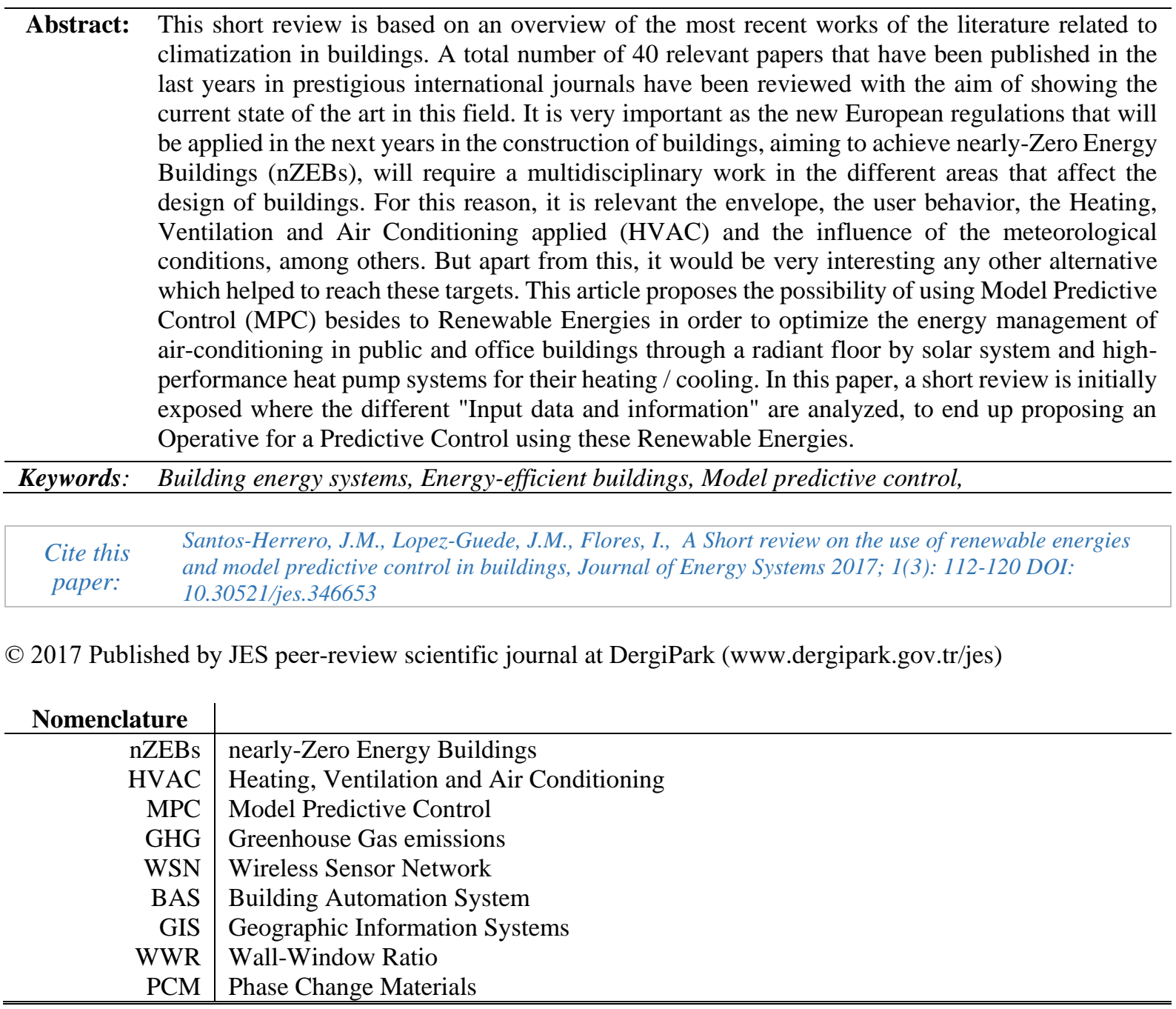




\section{INTRODUCTION}

The energy consumption required to air-condition any building is very high. According to several institutional reports, it accounts for $40 \%$ of the total energy generated in the world and therefore it would be causing one third of the total Greenhouse Gas emissions (GHG) [1,2,3]. Obviously, these data justify the importance of improving in this area to achieve sustainability. On the other hand, a number of studies developed in the last years as well as the technological advances in applications of buildings modelling and the databases existing at the present time allow us to be optimistic with the launch of new strategies to improve the efficiency at technical and economic level in the management of the climatization in buildings: Ruparathna et al. [4] summarize different energy efficiency improvement initiatives and define a road map for improving the energy performance of operating commercial and institutional buildings, Harish et al. [5] review modeling and control of building energy systems, Roberts [6] analyzes passive and active measures in existing buildings, Chandel et al. [7] show codes, standards, regulations and energy efficiency alternatives, Santos et al. [8] identify the factors which have influence on any building energy systems and Kneifel [9] estimates life-cycle energy savings of energy efficiency actions in new commercial buildings. For feasibility to carry out a project to air-conditioning public and office buildings will be analyzed: Firstly, we review several researches which have been published in the recent state of the art with the objective of showing the current situation in this field and the different existing focus. Secondly, with the tools revised and determining the ones considered more appropriate, it will be proposed a first working hypothesis. For that, we will have to consider the historical data of the climatological conditions and the Geospatial information of the location of a building, as well as the expected occupancy data and the comfort conditions required by the current legislation. Also, we must assess several HVAC systems with renewables energies, in order to reach the required comfort levels. Finally, it will be presented an approach of modeling through an energy performance simulation software for a public building with offices. It arises how minimize the energy demanded, through the definition of a series of "recipes" based on previous calculations made. These "recipes" could be applied according to the weather and occupancy forecast. This would allow to predefine a pattern of use in advance so that the predicted conditions of the building will conform to a predictable theory. For this purpose, several investigations have been reviewed, as shown in Table 1.

\section{LITERATURE REVIEW}

Through the articles and researches reviewed (a summary of all these works have been shown in the Table 1), one can observe the evolution of MPC for buildings in the last years. Starting from late 80s till nowadays, there are many researches which study the best way to develop a MPC and also multiple trials and implementations have been carried out.

García et al. [10] substantiated that MPC is an excellent control option because it takes into account the weather and occupancy forecast to find an optimal management of the energy. Cho et al. [11] probed strategies as a means of improving the energy efficiency of intermittently heated radiant floor heating systems. The results show that using the predictive control strategy could save between $10 \%$ and $12 \%$ energy. Oldewurtel et al. $[12,13,14]$ performed climate controls using Stochastic model predictive control. Široký et al. [15] developed an experimental analysis of model predictive control. Cigler et al. [16,17] made a MPC implementation in building. Fabietti et al. [18] controlled HVAC Systems via Explicit and Implicit MPC. Xiwang et al. [19] reviewed building energy modeling for control and operation. De Coninck et al. [20,21] developed a toolbox making validated grey-box building models and did practical implementation of MPC. 
Table 1. Overview of the literature about Predictive Control

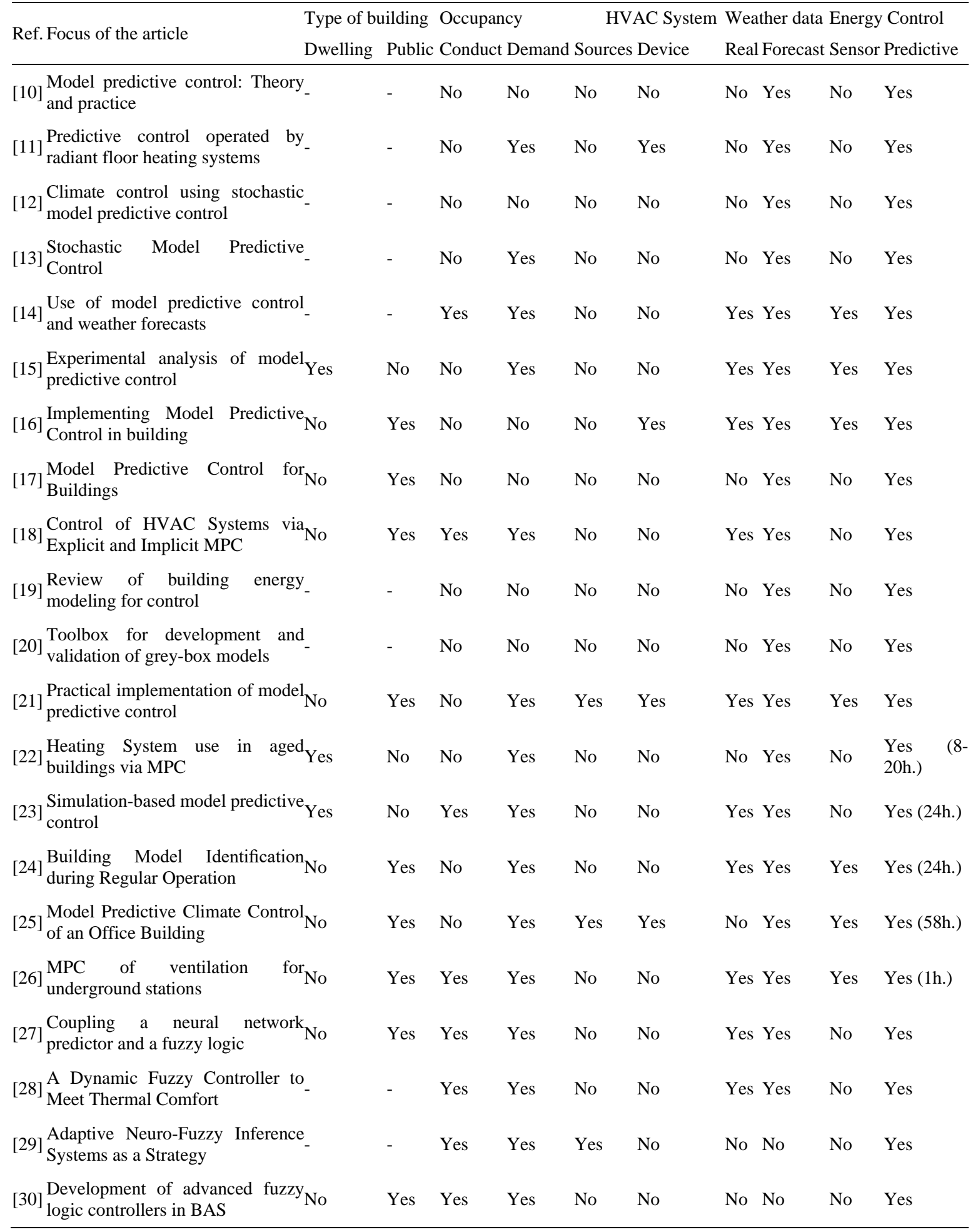

During the year 2016, some implementations of MPC in different locations and types of building were realized: Carrascal et al. [22] a dwelling building in the Basque Country (Spain), Ascione et al. [23] a residential building in Naples (Italy), Hu et al. [24] a public building in California (USA), Sturzenegger et al. [25] a office building in Allschwil (Switzerland) and Vaccarini et al. [26] in a underground station in Barcelona (Spain). In this last implementation, a Wireless Sensor Network (WSN) was used to know real data of occupancy, temperature, humidity, etc, because nowadays, there are many possibilities that would allow do it. Other example with a WSN is shown by Reena et al. [31] in their paper where the real occupancy was obtained by means of sensors and used to control indoor climate in a Building 
Automation System (BAS). A WSN could be considered the best way to avoid disturbances related with any alteration of temperature or occupancy information, because as indicated by Oldewurtel et al. [32], the occupancy information is a very important factor to reach a correct building climate control. Furthermore, nowadays these detectors could be harvesters because they would be more easily installed and maintained. Having a wireless network, it could transmit real data to a control system to make small adjustments in real time on the HVAC system. This would improve the efficiency because it could give a more appropriate response to the required comfort requirements and also, it would minimize the energy consumption of the building.

Finally, several papers have been reviewed which study different ways to manage the information and control the HVAC system, in order to have a nice comfort conditions but optimizing the energy consumption in the building: Marvuglia et al. [27] combined neuro-fuzzy model for indoor temperature dynamic and automatic regulation, Collotta et al. [28] proposed an artificial neural network to perform indoor temperatures forecast which were used to feed a fuzzy logic control unit, Dragomir et al. [29] identified the most used criteria, related to each modeling step, to define an optimal neural network forecasting tool and Ghadi et al. [30] developed an advanced fuzzy logic controllers in a smart building.

\section{INPUT DATA AND INFORMATION}

\subsection{Meteorological Data (Associated with a location)}

In developed countries it is easy to access to the databases available from governmental organizations and National Meteorological Institutes $[14,15]$ or even from meteorological stations located at airports or cities $[24,28]$. It is also possible to use applications which allow to calculate the incident solar radiation on flat surfaces arbitrarily oriented in any geographic location, for instance, Energyplus (http://www.eere.energy.gov/buildings/energyplus/) [16,23] or others site webs [18]. This information is possible complemented it with other climatic parameters such as temperature, cloudiness, infrared radiation, luminance, atmospheric pressure, wind speed and direction, etc.

\subsection{Usage Data and Occupancy of the Building}

The number of people or occupancy density, the duration of the occupancy, the nature of the activity carried out in a building, the type and power of the lighting and other electrical elements (for example, computers) or ventilation requirements as well as the infiltrations, are determinant to perform a correct simulation $[6,13]$.

It is also important to define its operation mode: continuous or intermittent, as well as a timetable of use at different seasons of the year.

It is complex to have a full certainty of this information. However, some standards can be defined according to the degree of occupancy forecast and the level of comfort required [32] with the possibility of making adjustments based on the actual data acquisition by field sensors [31]. This detector let us to know the real conditions and manage the HVAC system according to an optimal real demand. 


\subsection{HVAC System Design Data}

The type and operation of HVAC systems are fundamental, as well as their performance and their ability to achieve the required comfort values optimizing the energy required for it.

Furthermore, if the target is to minimize the economic cost, the electricity rates or fuels required in the HVAC system, they must be taken into account.

Firstly, considering the different existing HVAC systems, a radiant floor could be an efficient system as justified in $[33,34]$. It would allow for air-conditioning different areas of a building at a set point temperature pre-set in function of the weather forecast and occupancy. Moreover, it could take advantage of the thermal inertia of the building envelope to minimize the energy cost depending on the applicable energy rate in function of its schedule.

And finally, to improve the real requirements at different times, it would be possible to use a WSN that permits to know data of real temperature and occupancy online. For this last application of work Online, it is proposed to use high-performance heat pumps to adjust the comfort conditions demanded on a faster way and thereby avoid any disturbances in the system. These heat pumps can correct mismatches due to unexpected changes in the comfort and / or occupancy conditions. Nowadays, high performance heat pumps have a high efficiency and an excellent behavior as indicated in [35,36]. Both systems, radiant floor and high-performance heat pumps, have the capacity to heat or cool the space where they are installed. It is possible to adjust the air conditioning of the building during all the periods of the year, both in summer and winter.

\subsection{Building Modelling Data}

Each building is unique, not only due to its location but also for its orientation, geometry, dimensions and distribution of the zones, its characterization according to its construction type, the building materials used in its envelope, its surrounding conditions or the use of each one of its spaces.

It is obvious that the building envelope is one of the most important factors because it includes fenestration properties, Wall-Window Ratio (WWR), wall and roof material properties, air leakage or envelope sealing, natural ventilation, orientation, building configuration, day lit area, shape and height of the building $[37,38]$. For this reason, a correct modelling of the building is necessary to develop an outstanding investigation.

Obviously, the replacement of windows [39] or using Phase Change Materials (PCM) in the roof [40] to enhance its thermal performance, or any other improvement over the thermal insulation of the opaque envelopes of a building, it is very interesting, because they can reduce thermal losses of the building. But in many situations, a MPC could be more effective, easier, cheaper and with better energy savings.

\section{OPERATIVE FOR A PREDICTIVE CONTROL USING RENEWABLE ENERGIES}

Two levels are proposed for the control of the HVAC system: the first one is managed by means of a MPC. It is possible to anticipate the temperature / humidity conditions of the building according to the forecast of weather, occupancy and comfort requirements established. For this, the forecast of the meteorological data from a National Meteorological Institute or another source of confidence obtained by Internet with 24 hours in advance can be used [23,24]. Moreover, the schedule and timetable of the 
building would be taken into account in order to create several recipes. These recipes will be generated thanks to the modelling and subsequent simulations by means of building energy performance simulation program, to optimize the energy consumption considering the building thermal inertia as well as the energy cost. For example, in a working day in winter, when the activity in the building begins at 8:00 am, it could take advantage of the thermal storage capacity of the building [12,19], to run the heating through the radiant floor with some hours in advance, based on a work pattern defined in a recipe considered the most adequate depending on the weather and occupancy forecasts defined. Even considering the energy cost, because we cannot forget that in some countries, it has a variable cost according to a time range. And above all, the operation of the HVAC system would be running in a controlled way to avoid energy peaks and achieve important energy savings [15,21]. The main target would be for the building to reach the comfort conditions required in the occupancy hours expected. Within the temperature range of these comfort conditions, the temperature set point of each building space would be adjusted according to incident solar radiation, its albedo, WWR, wall and roof material properties, air leakage or envelope sealing, natural ventilation, orientation, building configuration, day lit area, shape and height of the building.

The obtained data could be managed in a control system using a family of controllers without expert intervention for a long time [10]. Nowadays, Grey-Box is considered the most adequate model [20]. For instance, Stochastic Model Predictive Control (SMPC) strategies have been successfully applied in different studies $[14,16,18]$ for energy efficient building climate control. Specifically, a Fuzzy Logic Controller (FLC) could be a nice way $[27,28,29,30]$ to manage the different recipes generated by TRNSYS application in function of the input signals available (forecasts and in real time). The objective would be optimize the control over the HVAC system, composed of radiant floor and high efficiency heat pumps, whose sources are renewable energies, to reduce energy consumption adjusting the heating or cooling depending on occupancy profile and comfort requirement defined.

With a second work mode, let's call it Online Mode, it would be used the high performance heat pumps because they can cool or heat the spaces of the building achieving a more flexible system. This would allow a faster response to sudden variations of conditions or simply any user could have a certain control over range temperature which it would improve its own sensation of comfort [6]. Online Mode would work with a WSN which would capture temperature and occupancy data in real-time of the different spaces of the building, it would make it possible to correct misalignments through the control of the high efficiency heat pumps. This approach with both indicated modes is shown in Figure 1:

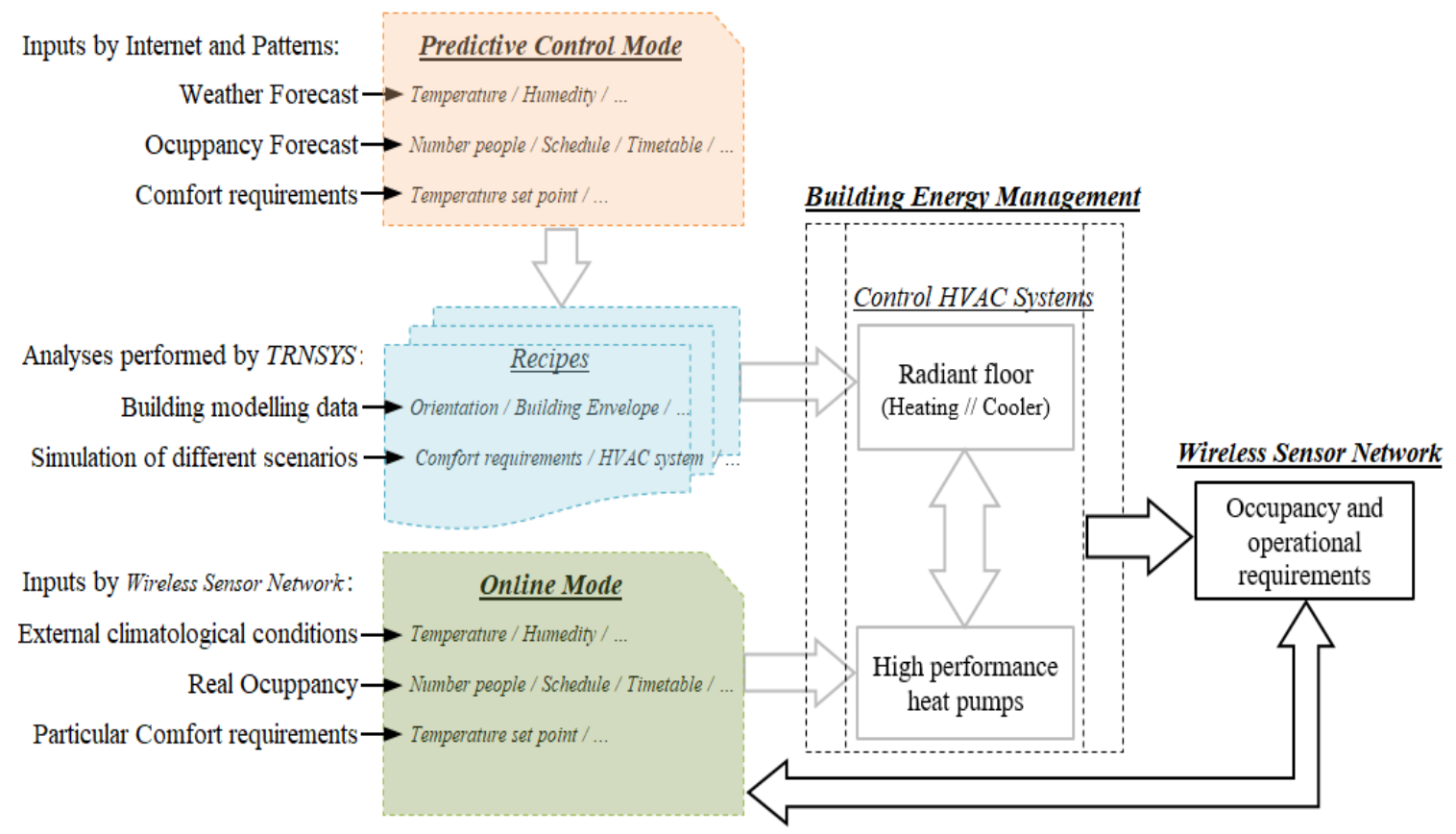

Figure 1. Scheme of the two working modes: Predictive and on-line. 


\section{CONCLUSIONS and FUTURE WORKS}

As it has been justified through the mentioned references, it is currently possible to improve the energy efficiency of any building with the available technologies and tools. But specifically in public and office buildings, the possibilities are huge with a predictive control system. It could be possible to manage a HVAC system with source from renewable energies, in an effective way, achieving considerable energy savings, and therefore, reducing $\mathrm{CO} 2$ emissions. It will be possible to reach the goal of ZERO EMISSIONS and in the not too distant future to have buildings that can supply themselves without external energy resources.

Our next work will be a review of the application of renewable energy in buildings, especially solar collectors used with a radiant floor and high efficiency heat pumps. Furthermore, we will consider developing a modeling of an office building in the Basque Country (Spain) by a building energy performance simulation program, for instance the TRNSYS application.

\section{Acknowledgment}

The authors are also grateful to European Union Ministry of Turkey, National Agency of Turkey for the support of this project under the Project Code: 2015-1-TR01-KA203-021342 entitled Innovative European Studies on Renewable Energy Systems.

\section{REFERENCES}

[1] United Nations Environment Programme, "Why buildings", $2015 . \quad$ Available: http://staging.unep.org/sbci/AboutSBCI/Background.asp (accessed on 24 April 2017).

[2] European Commission, "EU Energy in Figures. Statistical Pocketbook 2014, 2015 and 2016". Available: https://ec.europa.eu/energy/en/data-analysis/energy-statistical-pocketbook (accessed on 24 April 2017).

[3] U.S. Energy Information Administration, "Commercial Buildings Energy Consumption Survey 2012" and "Monthly Energy Review 2017”. Available: https://www.eia.gov/consumption/commercial/reports.php/.

[4] Ruparathna, R., Hewage, K., Sadiq, R., "Improving the energy efficiency of the existing building stock: A critical review of commercial and institutional buildings", Renewable and Sustainable Energy Reviews, 53, 1032-1045 (2015).

[5] Harish, V.S.K.V., Kumar, A., "A review on modeling and simulation of building energy systems", Renewable and Sustainable Energy Reviews, 56, 1272-1292, (2015).

[6] Roberts, S., “Altering existing buildings in the UK”, Energy Policy, 36, 4482-4486 (2008).

[7] Chandel, S.S., Sharma A., Marwaha B.M., "Review of energy efficiency initiatives and regulations for residential buildings in India", Renewable and Sustainable Energy Reviews, 54, 1443-1458 (2016).

[8] Santos-Herrero, J.M., Lopez-Guede, J.M., Flores, I., Sala, J.M., “An ongoing review on building energy efficiency improvement systems", $4^{\text {th }}$ European Conference on Renewable Energy Systems, Istanbul, 28-31 August 2016.

[9] Kneifel, J., "Life-cycle carbon and cost analysis of energy efficiency measures in new commercial buildings", Energy and Buildings, 42, 333-340 (2010).

[10] García, C.E., Prett, D.M., Morari, M., "Model predictive control: Theory and practice-A survey", Automatica, 25, 335-348 (1989).

[11] Cho, S.H., Zaheer-uddin, M., "Predictive control of intermittently operated radiant floor heating systems", Energy Conversion and Management, 44, 1333-1342 (2003).

[12] Oldewurtel, F., Parisio, A., Jones, C., Morari, M., Gyalistras, D., Gwerder, M., Stauch, V., Lehmann, B., Wirth, K., "Energy efficient building climate control using stochastic model predictive control and weather predictions", American Control Conference, 5100-5105, 30 June - 2 July 2010.

[13] Oldewurtel, F., "Stochastic Model Predictive Control for Energy Efficient Building Climate Control”, Ph.D. Dissertation ETH Zurich - No. 19908 (2011).

[14] Oldewurtel, F., Parisio, A., Jones, C., Gyalistras, D., Gwerder, M., Stauch, V., Lehmann, B., Morari, M., "Use of model predictive control and weather forecasts for energy efficient building climate control", Energy and Buildings, 45, 15-27 (2011). 
[15] Široký, J., Oldewurtel, F., Cigler, J., Prívara, S., "Experimental analysis of model predictive control for an energy efficient building heating system", Applied Energy, 88, 3079-3087 (2011).

[16] Cigler, J., Gyalistras, D., Široký, J., Tiet, V-N., Ferkla, L., "Beyond theory: the challenge of implementing Model Predictive Control in buildings", CLIMA 2013: 11th REHVA World Congress \& 8th International Conference on IAQVEC, Prague, 16-19 June 2013

[17] Cigler, J, "Model Predictive Control for Buildings", Ph.D. dissertation Czech Technical University in Prague Faculty of Electrical Engineering (2013).

[18] Fabietti, L., "Control of HVAC Systems via Explicit and Implicit MPC: An Experimental Case Study", Master's Degree Project of the KTH Electrical Engineering - No. XE-EE-RT 2014:006 (2014).

[19] Xiwang, L., Wen, J., "Review of building energy modeling for control and operation", Renewable and Sustainable Energy Reviews, 37, 517-537 (2014).

[20] De Coninck, R., Magnusson, F., Akesson, J., Helsen, L., “Toolbox for development and validation of greybox building models for forecasting and control", Journal of Building Performance Simulation, 9(3) (2015).

[21] De Coninck, R., Helsen, L., "Practical implementation and evaluation of model predictive control for an office building in Brussels", Energy and Buildings, 111, 290-298 (2016).

[22] Carrascal, E., Garrido, I., Garrido, A.J., Sala, J.M, “Optimization of the Heating System Use in Aged Public Buildings via Model Predictive Control”, Energies, 9, 251 (2016).

[23] Ascione, F., Bianco, N., De Stasio, C., Mauro, G.M., Vanoli, G.P., "Simulation-based model predictive control by the multi-objective optimization of building energy performance and thermal comfort", Energy and Buildings, 111, 131-144 (2015).

[24] Hu, Q., Oldewurtel, F., Balandat, M., Vrettos, E., Zhou, D., Tomlin, C.J., Building Model Identification during Regular Operation - Empirical Results and Challenges, IEEE American Control Conference, 6-8 July 2016.

[25] Sturzenegger, D., Gyalistras, D., Morari, M., Smith, R.S, "Model Predictive Climate Control of a Swiss Office Building: Implementation, Results, and Cost-Benefit Analysis", Control Systems Technology, 24(1) (2015).

[26] Vaccarini, M., Giretti, A., Tolve, L.C, Casals, M., "Model predictive energy control of ventilation for underground stations", Energy and Buildings, 116, 326-340 (2016).

[27] Marvuglia, A., Messineo, A., Nicolosi, G., "Coupling a neural network temperature predictor and a fuzzy logic controller to perform thermal comfort regulation in an office building", Building and Environment, 72, 287-299 (2014).

[28] Collotta, M., Messineo, A., Nicolosi, G., Pau, G., “A Dynamic Fuzzy Controller to Meet Thermal Comfort by Using Neural Network Forecasted Parameters as the Input", Energies, 7, 4727-4756 (2014).

[29] Dragomir, O.E., Dragomir, F., Stefan, V., Minca, E., “Adaptive neuro-fuzzy inference systems as a strategy for predicting and controling the energy produced from renewable sources", Energies, 8, 13047-13061, (2015).

[30] Ghadi, Y.Y., Rasul, M.G., Khan, M.M.K., "Design and development of advanced fuzzy logic controllers in smart buildings for institutional buildings in subtropical Queensland", Renewable and Sustainable Energy Reviews, 54, 738-744 (2015).

[31] Reena, M., Mathew, A.T., Jacob, L., "Energy Efficient Wireless Networked Building Automation System Controlled by Real Occupancy", TENCON 2015 - IEEE Region 10 Conference, Macau, 1-4 November 2015.

[32] Oldewurtel, F., Sturzenegger, D., Morari, M., "Importance of occupancy information for building climate control", Applied Energy, 101, 521-532 (2012).

[33] Hawila, A.W., Merabtine, A., Troussier, N., Mokraoui, S., Kheiri, A., Laaouatni, A., "Dynamic model validation of the radiant floor heating system based on the object oriented approach", 4. International Renewable and Sustainable Energy Conference, Marrakech, 14-17 November 2016.

[34] Sarbu, I., Sebarchievici, C., "Performance evaluation of radiator and radiant floor heating systems for an office room connected to a ground-coupled heat pump", Energies, 9, 228 (2016).

[35] Ruelens, F., Iacovella, S., Claessens, B.J., Belmans, R., "Learning agent for a heat-pump thermostat with a set-back strategy using model-free reinforcement learning", Energies, 8, 8300-8318, 2015.

[36] Tsai, H.L., "Design and Evaluation of a Photovoltaic / Thermal-Assisted Heat Pump Water Heating System", Energies, 7, 3319-3338 (2014).

[37] Susorova, I., Tabibzadeh, M., Rahman, A., Clack, H.L., Elnimeiri, M., "The effect of geometry factors on fenestration energy performance and energy savings in office buildings", Energy and Buildings, 57, 6-13 (2013).

[38] Lin, H-W., Hong, T., “On variations of space-heating energy use in office buildings”, Applied Energy, 111, 515-528 (2013).

[39] Aste, N., Caputo, P., Buzzetti, M., Fattore, M., "Energy efficiency in buildings: What drives the investments? The case of Lombardy Region", Sustainable Cities and Society, 20, $27-37$ (2016).

[40] Chung, M.H., Park, J.C., "Development of PCM cool roof system to control urban heat island considering temperate climatic conditions", Energy and Buildings, 116, 341-348 (2016). 